\title{
Juan Antonio Carrillo Salcedo 1934-2013
}

El 19 de enero de 2013 nos despertamos con el dolor inmenso que nos produjo la partida de nuestro querido y admirado maestro, el profesor Juan Antonio Carrillo Salcedo. Falleció en Sevilla, ciudad que le reconoció como uno de sus ciudadanos más ilustres.

Originario de Morón de la Frontera, el profesor Carrillo Salcedo fue un andaluz universal. Vino a estudiar Derecho a la Universidad de Sevilla, donde se licenció en 1956. Obtuvo el Grado de Doctor por esta misma Universidad en el 1958, con una tesis titulada: "La recepción del recurso contencioso-administrativo en el ordenamiento jurídico de la CECA", tesis dirigida por el profesor Mariano Aguilar Navarro, su maestro, que le hizo acreedor del Premio Extraordinario de Doctorado otorgado por nuestra Universidad.

Fue catedrático de Derecho Internacional Público y Privado en las Universidades de Granada (1963-1974) y Autónoma de Madrid (19741980). En 1980 regresó a Sevilla como catedrático de Derecho Internacional Público y Relaciones Internacionales, cátedra que ocuparía hasta su jubilación administrativa en el año 2005. En el ámbito de la gestión universitaria, fue decano de las Facultades de Derecho de las Universidades Autónoma de Madrid y Sevilla.

En 1959 obtuvo el Diploma cum laude de la Academia de Derecho Internacional de La Haya, siendo el primer español en obtener dicha distinción. Academia de Derecho Internacional de la que fue profesor en las sesiones de 1978, con un curso sobre Le renouveau du particularisme en droit international privé, y en 1996, en la que impartió el curso general de Derecho Internacional Público, con el título Droit International et souveraineté des Etats. Desde mayo de 2003 ocupó, asimismo, un puesto permanente en el Curatorium de esta afamada Institución. 
Fuera de España, don Juan Antonio (como todos le llamábamos) fue profesor habitual del Institut International des Droits de l'Homme, Estrasburgo; del Collège d'Europe, Brujas; de la Universidad de París (II); del Institut des Hautes Etudes Internationales, París, y del Institut Universitaire des Hautes Etudes Internationales, Ginebra; del Centro de Estudios Sociales de la Facultad de Economía, de la Universidad de Coimbra; de la Facultad de Derecho de la Universidad de Atenas, y de la Facultad de Derecho de la Universidad de Coimbra. Fue, asimismo, investigador en el Instituto Universitario Europeo de Florencia.

El profesor Carrillo Salcedo fue, por otro lado, miembro fundador de la Asociación Española de Profesores de Derecho Internacional y Relaciones Internacionales. Miembro del Instituto Hispano-Luso-Americano de Derecho Internacional desde 1977. Miembro del Institut de Droit International desde 1991. Miembro de la Societé française pour le droit international. Miembro del Institut International des Droits de l'Homme de Estrasburgo. Miembro de las Reales Academia de Ciencias Morales y Políticas (Madrid) y de la Real Academia Sevillana de Legislación y Jurisprudencia.

Formó parte del Consejo Editorial de la revista Derecho Comunitario Europeo (Centro de Estudios Políticos y Constitucionales, Madrid); de la European Journal of International Law (Florencia, Instituto Universitario Europeo); de la Revue Générale de Droit International Public (París), de la Rivista Internazionale dei Diritti dell'Uomo (Universidad Católica de Milán); y del Anuario Mexicano de Derecho Internacional (UNAM, Instituto de Investigaciones Jurídicas), entre otros.

Dirigió más de treinta tesis doctorales en las Universidades Autónoma de Madrid, Coimbra, Córdoba, Deusto, Granada, Las Palmas, Santander, y Sevilla. Fue distinguido, además, como Doctor Honoris Causa por las universidades Carlos III de Madrid, Málaga, Córdoba y Huelva.

Fue autor de más de ciento cincuenta estudios de Derecho Internacional Público, Derecho Internacional Privado y Relaciones Internacionales. En ellos, defendió siempre la idea de un orden internacional basado en el respeto de la dignidad humana, un orden internacional al servicio, en definitiva, de la humanidad. En 1965, ante la Sexta Comisión de la Asamblea General de las Naciones Unidas en Nueva York, manifestaba que "el Derecho internacional acaso está dejando de ser un orden exclusivamente distribuidor de competencias formales entre Estados para ser, 
además de esto, un orden creador de condiciones espirituales, sociales y materiales de paz. Un orden internacional social, frente al clásico Derecho internacional liberal, en un proceso de transformación semejante a lo que significa el Estado social de derecho, frente al concepto de Estado de derecho de finales del siglo XIX. Un derecho internacional, en suma, en pleno proceso de socialización y humanización”. Desde aquel entonces, el estudio de la evolución histórica de la sociedad internacional y su Derecho fue una constante en la labor científica del profesor Carrillo Salcedo.

Al margen de su fecunda vida académica y universitaria, que le ha hecho acreedor a las más altas condecoraciones, el profesor Carrillo Salcedo colaboró activamente con el gobierno central durante la época de la transición democrática, siendo uno de los principales impulsores de la nueva imagen de España ante el mundo, particularmente, como reconoce su fraternal amigo Marcelino Oreja Aguirre (ministro de Asuntos Exteriores de Adolfo Suárez), marcó la hoja de ruta del nuevo gobierno en materia de libertad, democracia y derechos humanos. En efecto, el profesor Carrillo Salcedo fue uno de los principales artífices de que el Estado español ratificará los principales instrumentos internacionales para la protección de los derechos humanos y las libertades fundamentales. Influyó decididamente, además, en la ratificación del Estatuto del Consejo de Europa por parte de España.

Fue siempre un europeísta convencido, pero, como él siempre reconocía, se sentía más próximo al Consejo de Europa que a la Unión Europea. Defendió a lo largo de su vida, predicando con el ejemplo, los valores de la integración europea: el pluralismo político, la preeminencia del derecho y el respeto de los derechos humanos y las libertades fundamentales.

En esta última materia, y precisamente en el seno del Consejo de Europa, fue el primer español elegido para ocupar un puesto en la Comisión Europea de Derechos Humanos (1979-1985). Posteriormente, fue elegido como magistrado del Tribunal Europeo de Derechos Humanos, cargo que ocupó entre 1986 y 1990.

Al margen de todos sus logros académicos y profesionales, quisiera destacar, si me permite el lector la licencia, al excelente ser humano, siempre preocupado por los demás, cercano y humilde, coherente y fiel a los valores y principios morales que le distinguieron a lo largo de su 
vida. Ningún dolor humano le resultaba ajeno, como aseguraba Federico Mayor Zaragoza (antiguo director general de la UNESCO con quien mantuvo una relación de amistad fraternal desde que coincidieron en la Universidad de Granada en la década de los sesenta). Era un auténtico placer conversar con él y con su distinguida esposa, nuestra querida Matilde Donaire, una mujer extraordinariamente humana, cercana, sensible y culta, una persona excepcional.

En mi memoria vivirá siempre la imagen de un ser humano extraordinario en toda la extensión de la palabra, a quien tuve la dicha de conocer y disfrutar, de quien tanto aprendí, una persona que, objetivamente, me cambió la vida al haberme dado una oportunidad y al haber creído en mí. Particularmente, recuerdo una mañana de abril de hace casi diez años cuando lo busqué para comunicarle que el Ministerio de Educación nos había concedido la ayuda que habíamos solicitado dentro del Programa de Formación de Personal Universitario. Me recibió en su despacho de la Real Fábrica de Tabacos y me dijo: "Eres el primer latinoamericano miembro de este Departamento y para mi tiene un valor simbólico importante: el próximo Papa tiene que ser latinoamericano". Esas palabras estarán siempre en mi memoria. Que cercano estaba ese momento, desafortunadamente llegó después de su partida.

El dolor que nos deja su fallecimiento es muy grande, el hueco que dejó en nuestras vidas difícilmente se podrá llenar, don Juan Antonio vivirá siempre en nosotros y su memoria nos inspirará para seguir luchando por un mundo más humano, más justo. La esperanza, que siempre distinguió a nuestro maestro, nos acompañará en el recorrido.

Como hace ya algunos años afirmara su querido amigo y discípulo Alejandro Rodríguez Carrión:

"Suele decirse que se van los mejores, quizá eso siempre resulte exagerado. Es cierto que la Historia se hace pese a los nombres pero no es menos cierto que ciertos nombres tienen la capacidad de hacer la Historia más profunda y convincente".

Descanse en paz nuestro Maestro.

\section{César Villegas Delgado*}

* Profesor de Derecho Internacional Público y Relaciones Internacionales de la Universidad de Sevilla. 